\title{
Prognostic value of wingless-type proteins in non-small cell lung cancer patients: a meta-analysis
}

\author{
Jiajia Jin ${ }^{1,2 *}$, Ping Zhan ${ }^{1 *}$, Hong Qian ${ }^{2}$, Xiaoxia Wang ${ }^{3}$, Masaru Katoh ${ }^{4}$, Kevin Phan $^{5}$, Jin-Haeng Chung ${ }^{6}$, \\ Tangfeng $\mathrm{Lv}^{1}$, Yong Song ${ }^{1}$; Written on behalf of the AME Lung Cancer Collaborative Group
}

${ }^{1}$ Department of Respiratory Medicine, Jinling Hospital, Nanjing University School of Medicine, Nanjing 210002, China; ${ }^{2}$ Medical School of Southeast University, Nanjing 210009, China; ${ }^{3}$ Intensive Care Unit, Inner Mongolia People's Hospital, Hohhot 010017, Inner Mongolia Autonomous region, China; ${ }^{4}$ Department of Omics Network, National Cancer Center, Tokyo, Japan; ${ }^{5}$ The Collaborative Research (CORE) Group, Macquarie University, Sydney, Australia; ${ }^{6}$ Department of Pathology and Respiratory Center, Seoul National University Bundang Hospital, Seongnam City, Republic of Korea

Contributions: (I) Conception and design: All authors; (II) Administrative support: Y Song, T Lv; (III) Provision of study materials or patients: J Jin, T Lv, Y Song; (IV) Collection and assembly of data: J Jin, P Zhan; (V) Data analysis and interpretation: J Jin, P Zhan; (VI) Manuscript writing: All authors; (VII) Final approval of manuscript: All authors.

*These authors contributed equally to this study.

Correspondence to: Tangfeng Lv. Department of Respiratory Medicine, Jinling Hospital, Nanjing University School of Medicine, \#305, East Zhongshan Road, Nanjing 210002, China. Email: bairoushui@163.com; Yong Song, MD, PhD. Department of Respiratory Medicine, Jinling Hospital, Nanjing University School of Medicine, \#305, East Zhongshan Road, Nanjing 210002, China. Email: yong_song6310@yahoo.com.

Background: Wingless-type protein (Wnt) signaling pathway plays a crucial role in the development of human malignancies, such as epithelial-to-mesenchymal transition (EMT) and the maintenance of cancer stem cells (CSCs). Several studies have shown that the expression levels of Wnt proteins, ligands of Wnt signaling pathway, are related to clinical outcomes of non-small cell lung cancer (NSCLC) patients. This meta-analysis aimed to assess the prognostic value of Wnts proteins in patients with NSCLC.

Methods: A multiple electronic literature search was conducted to identify all articles referring to the prognostic value of Wnt proteins in patients of NSCLC up to July 2016. Eligible studies were included in a meta-analysis in order to summarize the extracted data in terms of pooled hazard ratios (HRs) and their $95 \%$ confidence intervals (95\% CIs).

Results: Ten studies published between 2005 and 2015 were eligible for this meta-analysis. The total number of patients included was 1,805. The combined HR for all eligible studies evaluating the overall survival (OS) of NSCLC patients with positive Wnt expression was 1.60 (95\% CI: 1.39-1.84). The subgroup analysis showed both Wnt1 and Wnt5a are associated with clinical outcome of NSCLC patients.

Conclusions: Overexpression of Wnt proteins, as well as Wnt1 or Wnt5a alone, was markedly associated with adverse OS in lung cancer patients, suggesting that Wnts may act as a prognostic marker among NSCLCs.

Keywords: Meta-analysis; non-small cell lung cancer (NSCLC); precision medicine; prognostic significance; Wingless-type protein (Wnt)

Submitted Jul 26, 2016. Accepted for publication Aug 18, 2016.

doi: 10.21037/tlcr.2016.08.08

View this article at: http://dx.doi.org/ 10.21037/tlcr.2016.08.08 


\section{Introduction}

Lung cancer is a highly aggressive cancer. It represents the leading cause of cancer-related deaths worldwide, and nonsmall cell lung cancer (NSCLC) accounts for $80-85 \%$ of all lung cancers (1). Despite recent advancements in the diagnosis and treatment of NSCLC (2), the overall 5-year survival rate remains approximately $15(3,4)$. In clinical practice, disease stage and performance status are important and independent prognostic factors. However, there is an urgent need for the development of useful and potential prognostic biological markers (5).

The Wingless-type protein (Wnt) pathway plays a key role in the regulation of signaling pathway regulating cell proliferation, differentiation, apoptosis, and migration. Dysfunction of this pathway can contributes to and tumorgenesis $(6,7)$. The Wnt protein family consists of at least 19 secreted cysteine-rich glycoproteins, overexpression of which will ultimately leads to expression of target genes associated with tumorgenesis (8-11) and tumor progression (12). Several previous studies have investigated the clinical significance of Wnt proteins. $\mathrm{Xu}$ et al. (13) found that Wnt1-positive expression in patients with NSCLC was closely associated with short overall survival (OS). Yao et al. (14) showed that high level of Wnt5a expression was also related to poor outcomes among NSCLC patients.

Aiming to investigate the prognostic value of $\mathrm{Wnt}$ protein overexpression on survival of patients with NSCLC we performed a systematic review of the current literature and in order to summarize the available the available data and a meta-analysis of the eligible studies. A further attempt to investigate the variable results between different centers was also performed by assessing the heterogeneity among studies and the potential publication bias.

\section{Methods}

\section{Search strategy}

A multiple electronic health database search on all articles on the prognostic value of Wnt protein overexpression on survival of patients with NSCLC published up to July 2016 was performed and reference lists were thereafter manually searched for relevant articles. Mesh terminology used was: $(((($ survival[Title/Abstract]) OR prognosis[Title/ Abstract]) OR outcome[Title/Abstract])) AND ((nonsmall cell lung cancer[Title/Abstract]) OR NSCLC[Title/ Abstract])) AND ((wnt[Title/Abstract]) OR Wingless-type
protein[Title/Abstract]). We used the "Preferred Reporting Items for Systematic Reviews and Meta-Analysis (PRISMA)" guidelines, the recent extension of the PRISMA statement for network meta-analysis for the current meta-analysis (15).

\section{Inclusion criteria}

Studies were reviewed by two authors (Jiajia Jin, Ping Zhan) independently. Studies included in the current meta-analysis had to meet the following criteria: (I) must evaluate Wnt expression level in NSCLC patients by immunohistochemistry (IHC); (II) must involve NSCLC patients have been be diagnosed by the golden standard of histopathologic examinations; and (III) must concern connection between Wnt proteins and survival data with regard to lung cancer.

An extensive effort was made to minimize the impact of covert duplicate or metachronous republication from the same groups on the patient sample size; in these cases, only the latest report was included. Case reports, letters, review articles, or laboratory articles, were excluded of the current analysis.

\section{Data extraction and quality assessment}

The eligible studies were evaluated by two reviewers (Jiajia Jin and Ping Zhan) independently using the "NewcastleOttawa Scale" (NOS) to examine their quality $(16,17)$. All of the studies included were considered to be of high quality with a score more than five each one based on the NOS. Data retrieved from each report included the first author's name, publication year, country, histology, metastasis (TNM) stages, the number of patients, test methods, the percent of Wnt positivity, hazard ratio (HR) and 95\% confidence interval (CI) survival rates and Wnt type (Table 1). Patient outcome was defined as OS, calculated from the date of operation to the date of death or date of last follow-up.

\section{Statistical methods}

The HRs and their 95\% CIs were combined as the pooled effective value. If HRs and their $95 \%$ CIs were not given explicitly, they were extracted from Kaplan-Meier curves as Tierney described previously (26). A statistical test for heterogeneity using the I square test was performed (27). The I square value lies between $0 \%$ to $100 \%$ and it presented with a $95 \%$ CI; I square value over $50 \%$ is considered 
Table 1 Main characteristics and results of the eligible studies

\begin{tabular}{|c|c|c|c|c|c|c|c|c|c|c|}
\hline $\begin{array}{l}\text { First author, } \\
\text { year (ref.) }\end{array}$ & $\begin{array}{l}\text { Patients } \\
\text { source }\end{array}$ & Histology & Stage & $\mathrm{N}$ pts & Method & Primary antibody & $\begin{array}{c}\text { Positive } \\
(\%)\end{array}$ & $\mathrm{HR}(95 \% \mathrm{Cl})$ & $\begin{array}{l}\text { Survival } \\
\text { results }\end{array}$ & Wnt type \\
\hline $\begin{array}{l}\text { Huang } 2005 \\
\text { (18) }\end{array}$ & Japan & NSCLC & $|-|||$ & 123 & $\mathrm{IHC}$ & $\begin{array}{c}\text { Goat polyclonal } \\
\text { antibody Santa Cruz }\end{array}$ & 56.7 & $2.451(1.2-5.1)$ & Poor & Wnt5a \\
\hline $\begin{array}{l}\text { Nakashima } \\
2008(19)\end{array}$ & Japan & NSCLC & $|-| I \mid$ & 151 & $\mathrm{IHC}$ & $\begin{array}{c}\text { Rabbit polyclonal } \\
\text { antibody Santa Cruz }\end{array}$ & 40.4 & $1.983(1.216-3.236)$ & Poor & Wnt1 \\
\hline $\begin{array}{l}\text { Huang } 2008 \\
(20)\end{array}$ & Japan & NSCLC & $|-| I \mid$ & 216 & $\mathrm{IHC}$ & $\begin{array}{c}\text { Rabbit polyclonal } \\
\text { antibody Santa Cruz }\end{array}$ & 49.1 & $1.784(1.132-2.813)$ & Poor & Wnt1 \\
\hline $\begin{array}{l}\text { Nakashima } \\
2010(21)\end{array}$ & Japan & NSCLC & $|-| I \mid$ & 122 & $\mathrm{IHC}$ & $\begin{array}{c}\text { Rabbit polyclonal } \\
\text { antibody Santa Cruz }\end{array}$ & 53.3 & $1.45(0.63-3.34)$ & Negative & Wnt1 \\
\hline $\begin{array}{l}\text { Wang } 2010 \\
(22)\end{array}$ & China & NSCLC & I-IV & 115 & $\mathrm{IHC}$ & $\begin{array}{l}\text { Rabbit monoclonal } \\
\text { antibody Abcam }\end{array}$ & 62.6 & $1.41(0.84-2.36)$ & Negative & Wnt1 \\
\hline Xu 2011 (13) & Korea & NSCLC & I-IV & 262 & $\mathrm{IHC}$ & $\begin{array}{c}\text { Rabbit polyclonal } \\
\text { antibody Santa Cruz }\end{array}$ & 36.6 & 1.699 (1.039-2.778) & Poor & Wnt1 \\
\hline Yao 2014 (14) & China & NSCLC & I-IV & 205 & $\mathrm{IHC}$ & Abcam & 61.95 & $1.47(1.04-2.06)$ & Poor & Wnt5a \\
\hline Lu 2015 (24) & China & NSCLC & I-IV & 219 & $\mathrm{IHC}$ & Abcam & 35.6 & 1.774 (1.221-2.576) & Poor & Wnt5a \\
\hline $\begin{array}{l}\text { Huang } 2015 \\
\text { (25) }\end{array}$ & China & NSCLC & NM & 264 & $\mathrm{IHC}$ & $\begin{array}{l}\text { Rabbit monoclonal } \\
\text { antibody Abcam }\end{array}$ & 34.4 & 1.319 (1.001-1.739) & Poor & Wnt2 \\
\hline
\end{tabular}

IHC, immunohistochemistry; RT-PCR, reverse transcriptase PCR; NSCLC, non-small-cell lung cancer; AC, adenocarcinoma; HR, hazard ratio; $\mathrm{Cl}$, confidence interval; $\mathrm{N}$ pts, number of patients; $\mathrm{NM}$, not mentioned; Wnt, Wingless-type protein.

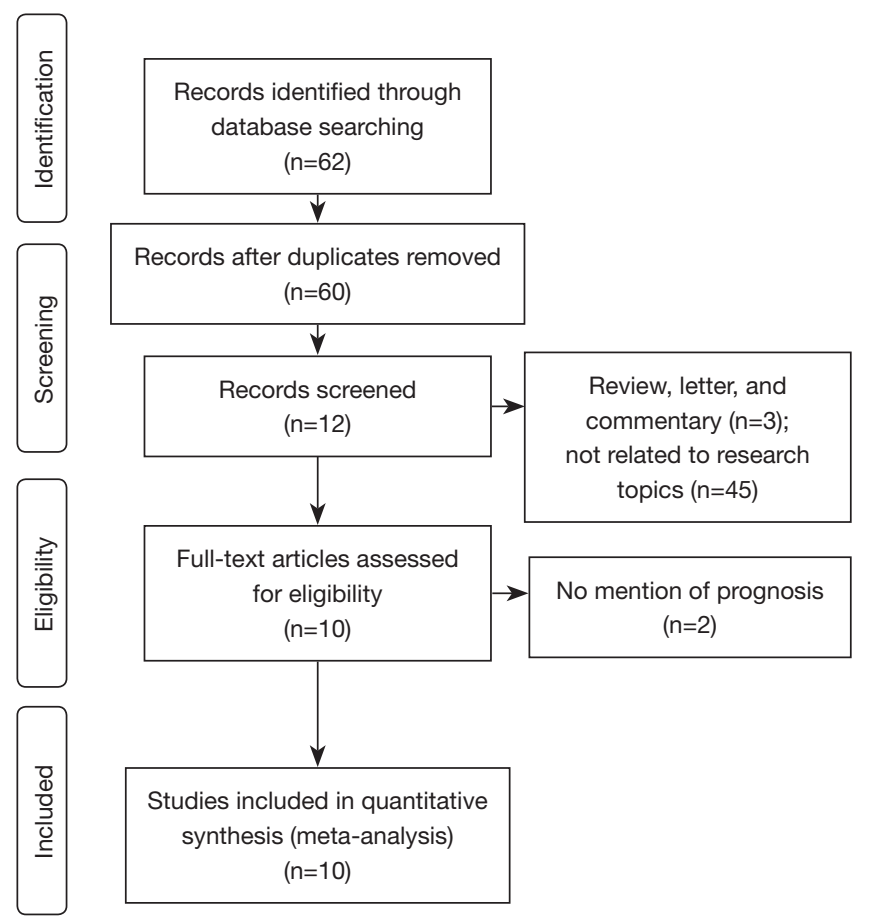

Figure 1 Flow diagram of the study selection in our meta-analysis. to indicate significant heterogeneity. The heterogeneity and robustness of pooled proportions were explored by conducing sensitivity analyses. However, because there are no published randomized clinical trials on this topic and all the reported studies are retrospective or prospective case series, the sensitivity analysis was limited to the exclusion of extreme studies as identified by the construction of funnel plots. The subgroup analysis was performed by Wnt type. Moreover, we assessed publication bias by Begg's funnel plots. Meta-analysis was conducted using STATA version 12.0 (Stata Corporation, College Station, TX, USA) statistical software.

\section{Results}

\section{Study selection and characteristics}

The electronic literature search yielded 112 citations, 10 of which fulfilled the inclusion criteria and were reviewed in the present study. Flow diagram of the study selection in our meta-analysis is shown in Figure 1. Ten observational studies published between 2005 and 2015 were eligible for final analysis. The total number of patients included 


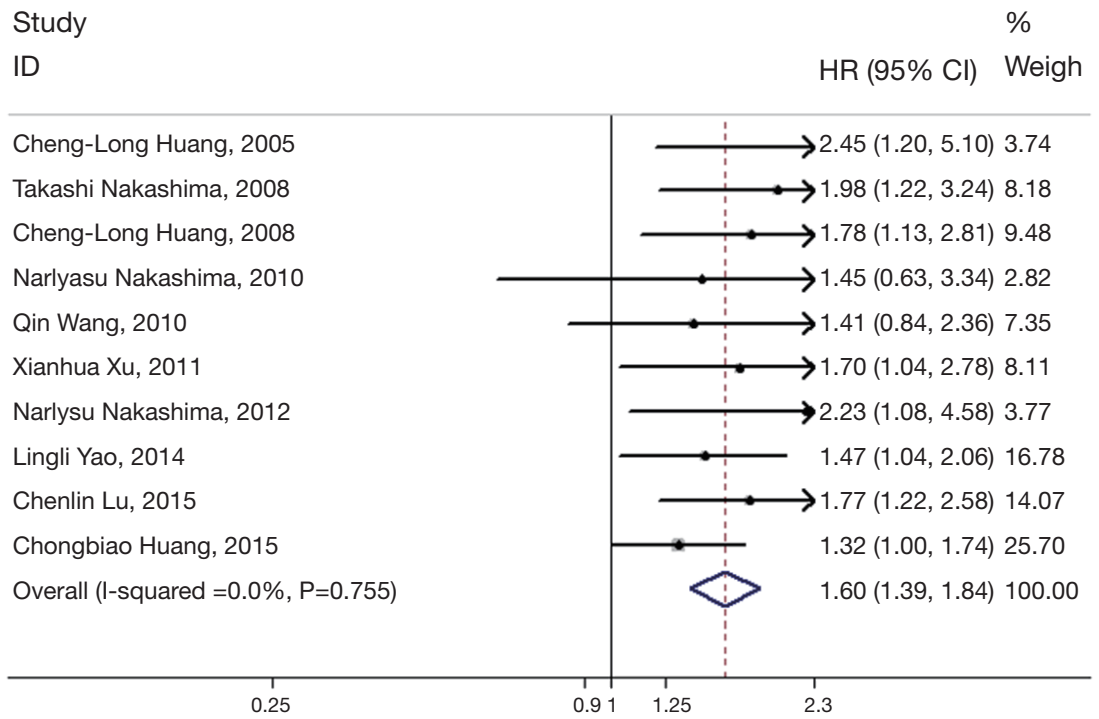

Figure 2 Meta-analysis of the association between positive Wnt expression and overall survival (OS) in patients with non-small cell lung cancer (NSCLC). Forest plot of hazard ratios (HRs) and 95\% confidence intervals (CIs) from each study were shown.

was 1,805 . The major characteristics of the ten eligible publications are reported in Table 1. The Wnt proteins investigated, including Wnt1, Wnt2, Wnt3 and Wnt5a, were all detected by cytoplasmic staining. The subgroup analysis was performed by Wnt protein type. Of the ten studies, five studies referred to the relation between Wnt1 positive expression and OS $(13,19-22)$, and three studies on Wnt5a $(14,18,24)$, and two studies the role of Wnt2 (25) and Wnt3 (23) respectively.

\section{Meta-analysis}

Overall, the pooled HR for the eligible studies evaluating the relation between Wnt proteins and OS was 1.60 (95\% CI: $1.39-1.84$ ) using the fixed effects model (Figure 2). The heterogeneity among the studies was not significant $\left(\mathrm{I}^{2}=0.0 \%\right.$, $\mathrm{P}=0.755)$. The subgroup analysis was performed by $\mathrm{Wnt}$ protein type. Five studies were found to investigate the role of Wnt1 (13,19-22), two studies the role of Wnt2 (25) and Wnt3 (23) respectively and three studies the role of Wnt5a $(14,18,24)$. Higher Wnt1 expression and Wnt5a expression were associated with poorer OS, as the pooled HR for OS was 1.69 (95\% CI: 1.34-2.14) and 1.68 (95\% CI: 1.32-2.13), respectively (Figure 3). Meanwhile, the heterogeneity among the studies was not significant $\left(\mathrm{I}^{2}=0.0 \%, \mathrm{P}=0.900\right.$ and $\mathrm{I}^{2}=0.0 \%, \mathrm{P}=0.424$, respectively).

There was no publication bias, as evidence by the symmetrical pattern of the funnel plots (Figure 4).

\section{Discussion}

The present meta-analysis revealed that NSCLC patients with a positive Wnt expression showed a shorter OS than patients with a negative Wnt expression. The subgroup analysis still showed that high Wnt1 and Wnt5a expression was markedly related to poor OS among patients. Thus, our results imply that Wnt proteins may play a role as prognostic biomarkers for predicting outcomes of NSCLC patients. There was no significant heterogeneity among the studies, whereas the potential publication bias was also low.

Some limitations of our meta-analysis should be noted. Firstly, the total sample size of the present meta-analysis $(\mathrm{n}=1,805)$ is limited by the available studies included, which constrains the statistical power of the analysis. The available studies were also all derived from Asian populations, and whether the present trends in this study can be applicable across all continents remains to be established. Secondly, some potential bias existed when HR was extracted from Engage Digitizer instead of obtained directly from published statistics. As such, data is estimated from the provided Kaplan-Meire curve for some studies which may yield some inaccuracies. Thirdly, antibody clones used were not uniform and methods to detect Wnt protein expression level were not unified. Despite the limitations mentioned above, to our knowledge, this is the first meta-analysis concentrated on the correlation of Wnt expression with prognosis of lung cancer. 


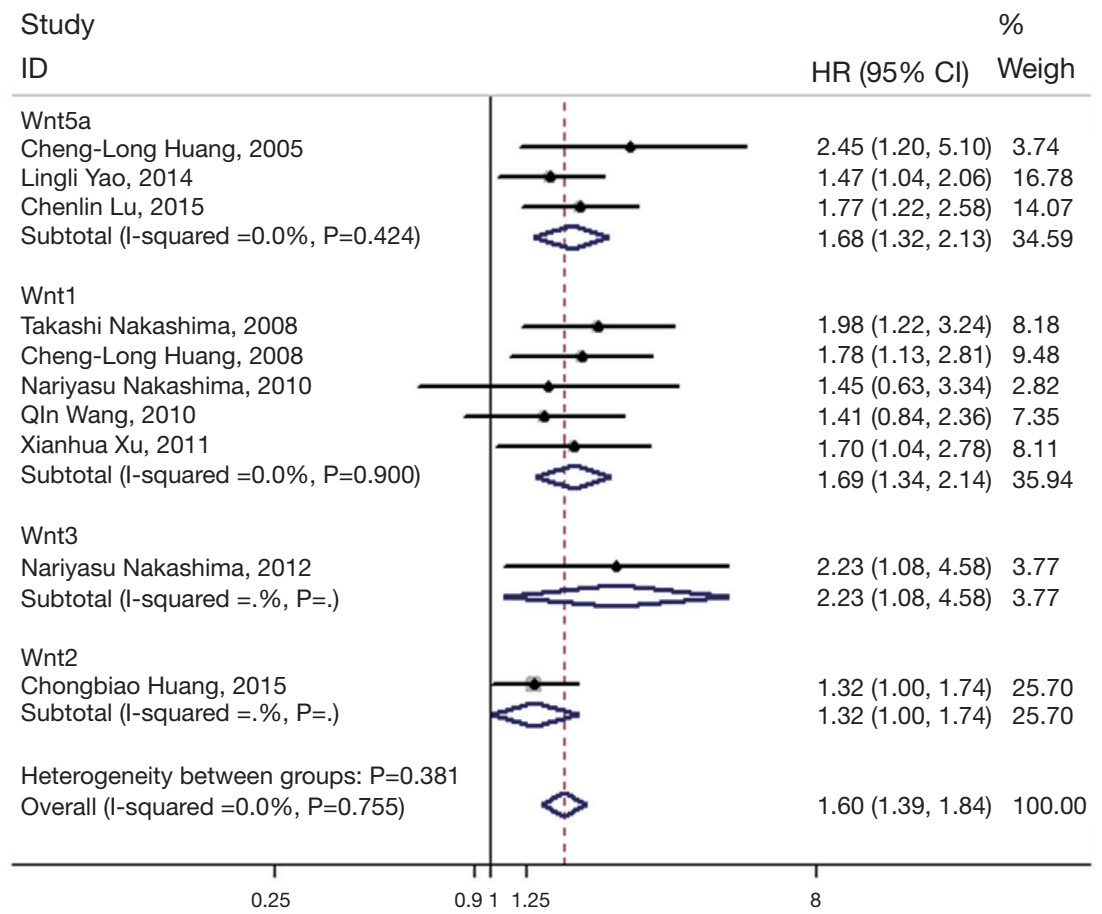

Figure 3 Subgroup analysis of the association between overall survival (OS) of non-small cell lung cancers (NSCLCs) and positive Wnt1 expression or Wnt5 expression. Forest plot of hazard ratios (HRs) and 95\% confidence intervals (CIs) from each study were shown.

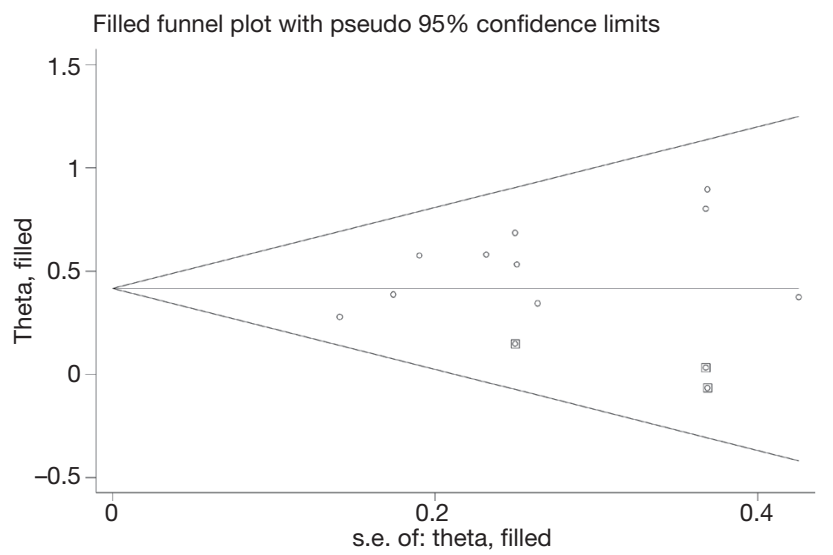

Figure 4 Begg's funnel plots for assessing potential publication bias on overall survival.

Wnt signals are transduced to the canonical and noncanonical cascades in a cellular context-dependent manner $(28,29)$. The most known Wnt signaling pathway is the canonical Wnt pathway, which signals through $\beta$-catenin. Other Wnt signaling pathways include the $\mathrm{Wnt} / \mathrm{Ca}^{2+}$ flux pathway (30,31), and the protein kinase A pathway (30), cJun N-terminal kinase (31), and the small GTPases Rho,
Rac, and Cdc 42 (31). Among 19 Wnt family members in of mammalian cells, Wnt 1 and Wnt3 preferentially activate the canonical Wnt signaling cascade, whereas Wnt5a preferentially activates non-canonical Wnt signaling cascades (28-31). Canonical Wnt signaling activation via the Frizzled family of receptors will finally contribute to the promotion of tumorigenesis through the expression of its target genes, such as Cyclin D1 and c-Myc $(31,32)$. Xu et al. (13) showed that Wnt1 expression was significantly associated with those of $\beta$-catenin and c-Myc in NSCLC; Nakashima et al. (23) found that Wnt3 expression in NSCLC was associated with c-Myc expression and tumor progression; Yao et al. (14) reported that Wnt5a contributes to NSCLC progression through the promotion of angiogenesis. Together these facts indicate that Wnt1, $W n t 3$ and $W n t 5 a$ are able to promote lung carcinogenesis.

Therapeutics targeting $A L K$ fusions and $E G F R$ mutations are in the clinical practice for NSCLC patients, and therapeutics targeting RET fusions, ROS1 fusions and FGFR1 amplification are in clinical trials for NSCLC patients in the world (33-36). However, recurrence after targeted therapies is inevitable owing to acquired mutations in the drug-target genes, activation of by-pass signaling 
pathways and epithelial-to-mesenchymal transition (EMT). Because the WNT signaling cascades are involved in the regulation of drug resistance and cell motility in human cancers $(12,37,38)$, upregulation of Wnt proteins might contribute to the poor prognosis of NSCLC patients through the mechanisms related to the maintenance of cancer stem cells (CSCs) and promotion of invasion and metastasis.

In summary, our meta-analysis reveals that the positive Wnt protein is significantly associated with poor OS in patients with NSCLC. The early detection of Wnt may be of great value in evaluating the clinical outcomes of NSCLC patients.

\section{Acknowledgements}

None.

\section{Footnote}

Conflicts of Interest: The authors have no conflicts of interest to declare.

\section{References}

1. Siegel RL, Miller KD, Jemal A. Cancer statistics, 2016. CA Cancer J Clin 2016;66:7-30.

2. Zappa C, Mousa SA. Non-small cell lung cancer: current treatment and future advances. Transl Lung Cancer Res 2016;5:288-300.

3. Molina JR, Yang P, Cassivi SD, et al. Non-small cell lung cancer: epidemiology, risk factors, treatment, and survivorship. Mayo Clin Proc 2008;83:584-594.

4. Alberg AJ, Ford JG, Samet JM, et al. Epidemiology of lung cancer: ACCP evidence-based clinical practice guidelines (2nd edition). Chest 2007;132:29S-55S.

5. Donnem T, Bremnes RM, Busund LT, et al. Gene expression assays as prognostic and predictive markers in early stage non-small cell lung cancer. J Thorac Dis 2012;4:212-3.

6. de Sousa E Melo F, Vermeulen L. Wnt Signaling in Cancer Stem Cell Biology. Cancers (Basel) 2016;8.

7. Anastas JN, Moon RT. WNT signalling pathways as therapeutic targets in cancer. Nat Rev Cancer 2013;13:11-26.

8. He TC, Sparks AB, Rago C, et al. Identification of c-MYC as a target of the APC pathway. Science 1998;281:1509-12.

9. Kim PJ, Plescia J, Clevers H, et al. Survivin and molecular pathogenesis of colorectal cancer. Lancet 2003;362:205-9.

10. Ma H, Nguyen C, Lee KS, et al. Differential roles for the coactivators CBP and $\mathrm{p} 300$ on TCF/beta-catenin-mediated survivin gene expression. Oncogene 2005;24:3619-31.

11. Zhang X, Gaspard JP, Chung DC. Regulation of vascular endothelial growth factor by the Wnt and K-ras pathways in colonic neoplasia. Cancer Res 2001;61:6050-4.

12. Stewart DJ. Wnt signaling pathway in non-small cell lung cancer. J Natl Cancer Inst 2014;106:djt356.

13. Xu X, Sun PL, Li JZ, et al. Aberrant Wnt1/beta-catenin expression is an independent poor prognostic marker of non-small cell lung cancer after surgery. J Thorac Oncol 2011;6:716-24.

14. Yao L, Sun B, Zhao X, et al. Overexpression of Wnt5a promotes angiogenesis in NSCLC. Biomed Res Int 2014;2014:832562.

15. Liberati A, Altman DG, Tetzlaff J, et al. The PRISMA statement for reporting systematic reviews and metaanalyses of studies that evaluate healthcare interventions: explanation and elaboration. BMJ 2009;339:b2700.

16. Moher D, Shamseer L, Clarke M, et al. Preferred reporting items for systematic review and meta-analysis protocols (PRISMA-P) 2015 statement. Syst Rev 2015;4:1.

17. Liu Y, Yuan D, Ye W, et al. Prognostic value of circulating endothelial cells in non-small cell lung cancer patients: a systematic review and meta-analysis. Transl Lung Cancer Res 2015;4:610-8.

18. Huang CL, Liu D, Nakano J, et al. Wnt5a expression is associated with the tumor proliferation and the stromal vascular endothelial growth factor--an expression in nonsmall-cell lung cancer. J Clin Oncol 2005;23:8765-73.

19. Nakashima T, Liu D, Nakano J, et al. Wnt1 overexpression associated with tumor proliferation and a poor prognosis in non-small cell lung cancer patients. Oncol Rep 2008;19:203-9.

20. Huang CL, Liu D, Ishikawa S, et al. Wnt1 overexpression promotes tumour progression in non-small cell lung cancer. Eur J Cancer 2008;44:2680-8.

21. Nakashima N, Huang CL, Liu D, et al. Intratumoral Wnt1 expression affects survivin gene expression in nonsmall cell lung cancer. Int J Oncol 2010;37:687-94.

22. Wang Q, Zhan P, Yu L, et al. The correlation between the expression of $\mathrm{Wnt} 1$ and prognosis in resected non-small cell lung cancer. Zhongguo Fei Ai Za Zhi 2010;13:586-90.

23. Nakashima N, Liu D, Huang CL, et al. Wnt3 gene expression promotes tumor progression in non-small cell lung cancer. Lung Cancer 2012;76:228-34.

24. Lu C, Wang X, Zhu H, et al. Over-expression of ROR2 
and Wnt5a cooperatively correlates with unfavorable prognosis in patients with non-small cell lung cancer. Oncotarget 2015;6:24912-21.

25. Huang C, Ma R, Xu Y, et al. Wnt2 promotes non-small cell lung cancer progression by activating WNT/betacatenin pathway. Am J Cancer Res 2015;5:1032-46.

26. Tierney JF, Stewart LA, Ghersi D, et al. Practical methods for incorporating summary time-to-event data into metaanalysis. Trials 2007;8:16.

27. Higgins JP, Thompson SG, Deeks JJ, et al. Measuring inconsistency in meta-analyses. BMJ 2003;327:557-60.

28. Katoh M, Katoh M. WNT signaling pathway and stem cell signaling network. Clin Cancer Res 2007;13:4042-5.

29. Stewart DJ. Tumor and host factors that may limit efficacy of chemotherapy in non-small cell and small cell lung cancer. Crit Rev Oncol Hematol 2010;75:173-234.

30. Takahashi-Yanaga F, Kahn M. Targeting Wnt signaling: can we safely eradicate cancer stem cells? Clin Cancer Res 2010;16:3153-62.

31. Mazieres J, He B, You L, et al. Wnt signaling in lung cancer. Cancer Lett 2005;222:1-10.

Cite this article as: Jin J, Zhan P, Qian H, Wang X, Katoh M, Phan K, Chung JH, Lv T, Song Y; Written on behalf of the AME Lung Cancer Collaborative Group. Prognostic value of wingless-type proteins in non-small cell lung cancer patients: a meta-analysis. Transl Lung Cancer Res 2016;5(4):436-442. doi: 10.21037/tlcr.2016.08.08
32. Teng Y, Wang X, Wang Y, et al. Wnt/beta-catenin signaling regulates cancer stem cells in lung cancer A549 cells. Biochem Biophys Res Commun 2010;392:373-9.

33. Mano H. ALKoma: a cancer subtype with a shared target. Cancer Discov 2012;2:495-502.

34. Camidge DR, Pao W, Sequist LV. Acquired resistance to TKIs in solid tumours: learning from lung cancer. Nat Rev Clin Oncol 2014;11:473-81.

35. Katayama R, Lovly CM, Shaw AT. Therapeutic targeting of anaplastic lymphoma kinase in lung cancer: a paradigm for precision cancer medicine. Clin Cancer Res 2015;21:2227-35.

36. Katoh $M$, Nakagama H. FGF receptors: cancer biology and therapeutics. Med Res Rev 2014;34:280-300.

37. Takebe N, Miele L, Harris PJ, et al. Targeting Notch, Hedgehog, and Wnt pathways in cancer stem cells: clinical update. Nat Rev Clin Oncol 2015;12:445-64.

38. Miyamoto DT, Zheng Y, Wittner BS, et al. RNASeq of single prostate CTCs implicates noncanonical Wnt signaling in antiandrogen resistance. Science 2015;349:1351-6. 